\title{
Gestação com suspeita/diagnóstico de infecção pelo Zika Vîrus
}

\author{
Suspected pregnancy and diagnosis of Zika virus infection \\ Embarazo con sospecha/diagnóstico de infección por el virus del Zika
}

\begin{abstract}
RESUMO
Trata-se de estudo qualitativo, utilizando como instrumento de coleta de dados entrevista semiestruturada. A saturação dos dados se deu pela riqueza dos dados, procedendo a análise de conteúdo, na modalidade da análise temática. Foram entrevistadas 04 gestantes, uma puérpera e um cônjuge. Após análise, foram identificadas duas categorias temáticas, sendo elas: os saberes sobre o Zika Vírus e suas complicações; e repercussões e apoios cotidianos na gestação com suspeita ou diagnóstico de Zika Vírus. O saber mobilizado pelas pessoas que vivenciam o agravo enfatizou o aspecto estrutural da cabeça do bebê, que apontou preocupação com a questão da deficiência e da aparência física. As repercussões no cotidiano da gestante e do seu entorno promoveram a reorganização dos vínculos sociais, alcançando dimensões da vida privada, com destaque para dimensão socioeconômica e espiritualidade. A experiência diante dessa situação se repercutiu nas projeções e nos planos familiares, no compasso de questões morais que sedimentam as ações e as escolhas na esfera pública e privada.
\end{abstract}

DESCRITORES: Complicações na Gravidez; Zika Vírus; Microcefalia.

\section{ABSTRACT}

This is a qualitative study, using semi-structured interviews as a data collection instrument. Data saturation was due to the wealth of data, proceeding to content analysis, in the form of thematic analysis. Four pregnant women were interviewed, a puerperal woman and a spouse. After analysis, two thematic categories were identified, namely: knowledge about the Zika Virus and its complications; and repercussions and daily support in pregnancy with suspected or diagnosed Zika virus. The knowledge mobilized by the people who experience the disease emphasized the structural aspect of the baby's head, which pointed to concern with the issue of disability and physical appearance. The repercussions on the daily life of the pregnant woman and her surroundings promoted the reorganization of social bonds, reaching dimensions of private life, with emphasis on the socioeconomic dimension and spirituality. The experience in the face of this situation had repercussions on family projections and plans, on the rhythm of moral issues that sediment actions and choices in the public and private sphere.

DESCRIPTORS: Pregnancy Complications; Zika Virus; Microcephaly.

\section{RESUMEN}

Este es un estudio cualitativo, que utiliza entrevistas semiestructuradas como instrumento de recopilación de datos. La saturación de datos se debió a la gran cantidad de datos, que procedió al análisis de contenido, en forma de análisis temático. Se entrevistó a cuatro mujeres embarazadas, una mujer puerperal y un cónyuge. Después del análisis, se identificaron dos categorías temáticas, a saber: conocimiento sobre el virus del Zika y sus complicaciones; y repercusiones y apoyo diario en el embarazo con el virus Zika sospechado o diagnosticado. El conocimiento movilizado por las personas que experimentan la enfermedad enfatizó el aspecto estructural de la cabeza del bebé, lo que señaló la preocupación por el problema de la discapacidad y la apariencia física. Las repercusiones en la vida cotidiana de la mujer embarazada y su entorno promovieron la reorganización de los lazos sociales, alcanzando dimensiones de la vida privada, con énfasis en la dimensión socioeconómica y la espiritualidad. La experiencia frente a esta situación tuvo repercusiones en las proyecciones y planes familiares, en el ritmo de los problemas morales que sedimentan las acciones y elecciones en la esfera pública y privada. DESCRIPTORES: Complicaciones del Embarazo; Zika Virus; Microcefalia.

RECEBIDO EM: 14/08/2020 APROVADO EM: 24/08/2020 


\section{Laura do Espírito Santo Soares}

Enfermeira.

ORCID: 0000-0001-5303-2717

\section{Gênesis Vivianne Soares Ferreira Cruz}

Enfermeira

ORCID: 0000-0002-3248-1182

\section{Fabiane Blanco Silva Bernardino}

Enfermeira. Docente da Universidade Federal do Mato Grosso.

ORCID: 0000-0003-0339-9451

Andréia Lara Lopatko Kantoviscki

Enfermeira. Mestre em Enfermagem.

ORCID: 0000-0003-3674-0177

\section{Everton Rossi}

Enfermeiro. Mestre em Saúde Coletiva.

ORCID: 0000-0002-1945-0744

Manuela Ribeiro Moraes Dias

Enfermeira.

ORCID: 0000-0001-9787-2101

\section{INTRODUÇÃO}

E m novembro de 2015, o Ministério da Saúde trouxe um alerta sobre a relação entre a infecção pelo Zika Vírus (ZIKV) em gestantes e o nascimento de recém- nascidos com microcefalia no território brasileiro, sendo, posteriormente, confirmada a existência dessa associação pela Organização Mundial da Saúde e pelo United States Centers for Disease Control and Prevention ${ }^{(1-3)}$.

A transmissão do ZIKV pode ocorrer pelo mosquito vetor Aedes aegypti, mas, também, pela transfusão sanguínea e pela via sexual ${ }^{(3)}$. A microcefalia se tornou uma das mais conhecidas formas clínicas da infecção congênita nos recém-nascidos, no entanto, existem outras manifestações clínicas abarcadas pela Síndrome Congênita do Zika Vírus - SCZV ${ }^{(4,5)}$, devido sua capacidade de atingir o sistema nervoso central, afetando o crescimento e desenvolvimento fetal, e ocasionar alterações físicas, neuromotoras e cognitivas ${ }^{(4,6)}$.

A SCZV é considerada uma condição crônica que afeta diretamente a família, exigindo dos pais o contato frequente com os profissionais e serviços de saúde e a necessidade de cuidados permanentes da criança acometida. A microcefalia e a infecção pelo ZIKV podem ser diagnosticadas na gestação, gerando apreensão e incertezas por parte da família diante da suspeita ou diagnóstico, principalmente dos pais ${ }^{(7)}$, pois, para muitos casos, o tratamento é imprevisível ou pouco acessível. Considera-se, portanto, relevante compreender a experiência de gestantes com suspeita ou diagnóstico de ZIKV pela necessidade de um olhar mais sensível às singularidades e subjetividades envolvidas em seus desdobramentos.

Neste cenário, valorizar os aspectos subjetivos daqueles que sentem na pele tais acontecimentos (gestantes, cônjuges), pode provocar reflexões sobre o cuidado, o cotidiano e os significados da assistência frente essa condição crônica. Entende-se a experiência como o resultado de múltiplas vivências condensadas em significados particulares e que expressam algum sentido para a pessoa que a vivenciou, sendo perpassada, contudo, por elementos objetivos $^{(8)}$. Se envolvem significados, pressupõe a interpretação, na qual os sujeitos dispõem de um estoque de conhecimento prévio $^{(9)}$. A experiência é o que revela o modo de ser no mundo e o meio pelo qual o mundo se coloca em nossa face e den- tro de nós ${ }^{(10)}$, se referindo, também, aos "meios pelos quais os indivíduos e grupos sociais respondem a um dado episódio de doença"(11).

Propôs-se compreender alguns aspectos da experiência de gestantes, puérpera e cônjuge diante da suspeita ou diagnóstico de ZIKV, atendidos em um serviço de referência do Estado de Mato Grosso, Brasil. Emergiram as seguintes perguntas norteadoras: Qual o saber mobilizado pelas gestantes, puérperas e cônjuges sobre o ZIKV na gestação? Quais as repercussões desse agravo no cotidiano? E quais possibilidades de apoio surgiram?

\section{METODOLOGIA}

Trata-se de um estudo qualitativo realizado em um serviço de referência para o atendimento ambulatorial e internação de gestantes com suspeita ou diagnóstico de ZIKV, entre os meses de janeiro e junho de 2018, o qual foi devidamente aprovado pelo Comitê de Ética em Pesquisa com seres humanos, sob o parecer $\mathrm{n}^{\circ} 1.842 .018 \mathrm{e}$ CAAE: 59553716.9 .0000 .5541$.

A seleção dos participantes foi intencional, mediante convite pessoal durante as visitas técnicas ao local selecionado para 
a pesquisa. Os critérios de inclusão foram: ser maior de 18 anos e receber atendimento no serviço de saúde relacionado à suspeita ou diagnóstico de infecção pelo ZIKV no período gestacional. A delimitação do número de participantes foi feita a partir da riqueza dos dados coletados nas entrevistas. De acordo com Minayo ${ }^{(12)}$, uma amostra qualitativa ideal é aquela que reflete, em quantidade e intensidade "as múltiplas dimensões de determinado fenômeno". Ao todo, foram 06 participantes da pesquisa: quatro gestantes, uma puérpera e um cônjuge, os quais nos trechos de falas trazidos são identificados pelo código $G$ para gestante, seguido de numeração aleatória (G1, G2, G3 e G4), Puérpera e Cônjuge, respectivamente.

Para a produção de dados foi realizada entrevista com roteiro semiestruturado e a análise de conteúdo, na modalidade da análise temática, orientou seu tratamento ${ }^{(13)}$. As discussões foram organizadas em duas categorias temáticas: Os saberes sobre o Zika Vírus e suas complicações e Repercussões e apoios cotidianos na gestação com suspeita ou diagnóstico de Zika Vírus.

\section{RESULTADOS}

Todas as gestantes eram casadas, idade entre 22 e 32 anos, no período da entrevista a idade gestacional variou entre 23 a 39 semanas, três delas estavam internadas com suspeita de ZIKV e apresentavam comorbidades, como: diabetes gestacional, hipertensão, pneumonia e anemia. Nenhuma delas estava acompanhada do cônjuge durante a internação. Duas participantes foram selecionadas enquanto aguardavam atendimento no setor de triagem do serviço ambulatorial. Uma delas foi entrevistada após receber resultado positivo de exame laboratorial para ZIKV e estava acompanhada pelo marido de 32 anos, que também participou da pesquisa. A puérpera, no segundo dia pós-parto, estava internada sem acompanhante e o recém- nascido estava na Unidade de Terapia Intensiva Neonatal, com diagnóstico de microcefalia por ZIKV.
A experiência das mulheres com suspeita e diagnóstico da infecção pelo ZIKV se mostrou como fenômeno sensível ao corpo, possuindo um importante papel para o seu delineamento, enquanto modo de viver/estar no mundo $(10,14)$. Isso porque é no corpo que se evidenciam os sinais de adoecimento e é nele que incidem as intervenções cotidianas, seja de prevenção, diagnóstico e cuidados do agravo.

Entre as manifestações corporais de sintomas da infecção do ZIKV, foram citadas:

"Dor nas articulações, no músculo, dor de cabeça, febre, náuseas, tontura, coceira, tipo, pra mim era sarna, parecia sarna, tava muito grossa [a pele]." (G2).

"Inchaço nas juntas e nos tornozelos, nas mãos, o corpo bastante avermelhado [...] tá empolado ain$d a[. .$.$] as manchas não sumirame$ febre, febre alta [...] estava com $39^{\circ}$ de febre e muita dor de cabeça, dor no corpo" (G4).

Para além do corpo, os aspectos subjetivos trouxeram o saber mobilizado pela experiência diante da suspeita ou diagnóstico da infecção pelo ZIKV, o qual apresenta- se a seguir.

\section{Saberes sobre o Zika Vírus e suas possíveis consequências na gestação}

A experiência possui aspectos tanto subjetivos como intersubjetivos, que pressupõem a existência de quadros de referência - internalizados pelos sujeitos por meio de processos concretos de interação social $^{(11)}$, que mobilizam os mais variados saberes que circulam no meio social, inclusive aqueles sobre o ZIKV e a microcefalia.

Para Schutz ${ }^{(9)}$, o que uma pessoa sabe em sua vida cotidiana "é qualquer coisa que ela acha que seja conhecimento", que diz respeito a questões práticas, constituindo seu estoque de conhecimento. $\mathrm{Na}$ experiência do adoecimento, o sentir- se mal ou o sentir que algo inesperado pode acontecer - como o nascimento de um bebê com microcefalia - coloca em movimento os saberes e a capacidade de transformar essa experiência em conhecimento ${ }^{(11)}$.

"O que eu sei, é que o bebê pode nascer com má formação [...] Eu sei que a criança nasce com a cabeça pequena" (G4).

“[...] ele [o ZIKV] destrói alguma coisa na cabeça do bebê e aí ele pode nascer com microcefalia" (Puérpera).

\begin{abstract}
"Eu sei que ele [o ZIKV], quando a gente é infectado, ele pode dar microcefalia na criança no começo da gestação [...] eu não tenho certe$z a$ se do meio pro fim acontece isso, mas no começo da gestação pode sim ocasionar essa doença [...]" (G2).
\end{abstract}

As falas podem revelar que o saber mobilizado pelas pessoas que vivenciam o agravo enfatiza o aspecto estrutural da cabeça do bebê - tamanho, deformidade - que aponta para a preocupação com a deficiência e a aparência. Nesse sentido, o conhecimento prático e cotidiano de cada pessoa pode lhe servir como um esquema interpretativo de experiências passadas, presentes e até antecipando ocasiões do por vir, como o nascimento de uma criança com microcefalia.

Nas questões que envolvem a deficiência física, especialmente daquelas mais visíveis e identificáveis (corporificadas na aparência), como é no caso da microcefalia, os saberes podem denunciar a diferença $^{(15)}$ ao se relacionar com o estigma - que remete a um atributo depreciativo e que pode se manifestar na linguagem das relações ${ }^{(16)}$, evidenciando uma característica diferenciada daquilo que é previsto como uma norma social ("um bebê saudável").

De fato, a microcefalia é a manifestação clínica mais conhecida entre os entrevistados e, também, a mais propagada socialmente. Porém, é importante lembrar que se trata de uma das formas clínicas da $\mathrm{SCZV}$, que pode cursar com as mais diversas manifestações e alterações ${ }^{(5)}$.

No cotidiano existem vários meios 
de divulgação e de informações sobre o ZIKV e a microcefalia, tais como: a rede social, campanhas oficiais de prevenção, orientações fornecidas pelos profissionais de saúde no acompanhamento pré-natal, bem como, pela interação social com pessoas de seu entorno (familiares, vizinhos, colegas, comunidade, etc.); constituindo, desse modo, importantes matrizes de significados e de práticas (referências), onde as experiências prévias são sedimentadas e organizadas como conhecimento à mão ${ }^{(9)}$, facilmente acessado e interpretado.

Os saberes mobilizados (disponíveis) no cotidiano circulam/propagam de forma dinâmica na sociedade e são diversamente apropriados pelos sujeitos, os quais são culturalmente construídos, elaborados e $\operatorname{articulados}{ }^{(17)}$, como nos noticiários $\mathrm{e}$ nas mídias televisivas:

"Ai, de uma hora pra outra, você sabe que sua mulher tá com esse vírus da zika [...] você já sabendo pela televisão o que causa" (Cônjuge).

"Eu não conheço muito. Só vi o que passava na televisão, né? Naquela época que teve surto. Aí, via assim, mais ou menos, mas nunca me aprofundei não [...] Só via a questão da microcefalia" (G1).

Notou-se que a mídia estava presente na vida cotidiana e que suas conexões midiáticas poderiam ser úteis para trazer informações, (re)produzir e partilhar os significados socioculturais diante do agravo. Além de transmitir conteúdo simbólico, os meios de comunicação também podem influenciar na formação do pensamento político e social ${ }^{(18)}$, contudo, tal processo não é algo mecânico e passivo, pois há de se considerar a capacidade das pessoas na (re)elaboração e na (re)integração dos saberes para a composição do estoque de conhecimento.

De modo que, "até mesmo as ideias culturais mais estereotipadas existem somente na mente dos indivíduos que as absorvem, e que as interpretam com base em suas próprias situações de vida"(9), confe- rindo a elas um registro pessoal e singular. Ou seja, as pessoas não utilizam exclusivamente de informações específicas sobre o ZIKV e a microcefalia fornecidas pela mídia popular e/ou científica, pela possibilidade de se aportar em conhecimentos/ ideias sobre outras condições que afetam o corpo (física e mentalmente), que lhes foram transmitidos anteriormente e que são atualizadas e ressignificadas na situação cotidiana que se lhes apresenta.

Assim, nas diversas situações do mundo da vida as pessoas podem ser conduzidas à reflexão e interpretações nos contextos socioculturais compartilhados com outros - mundo intersubjetivo ${ }^{(14)}$. De modo prático, no que diz respeito aos cuidados com o corpo das mulheres, os saberes sobre as formas de transmissão do ZIKV também são importantes para se pensar em medidas mais efetivas para a prevenção do agravo $^{(19)}$ e que estejam mais coerentes com a realidade.

Os depoimentos revelaram maior ênfase da transmissão do vírus pelos mosquitos vetores e na adoção de medidas de controle sobre o ambiente que são mais amplamente divulgados nos meios de comunicação social:

"[disseram] que era pra mim passar repelente, que era pra mim evitar roupas escuras [...] limpar minha casa, num deixar água, pneu assim, água no pneu, essas coisas [...]" (Puérpera).

"Em casa mesmo não deixamos nada de água parada, sempre cuidando, entendeu? Tela [antimosquito] [...] ela [a gestante] passando o protetor dela também - os repelentes [...]" (Cônjuge).

Não obstante, outro depoimento reproduziu elementos do saber biomédico menos divulgados:

\section{"[o ZIKV é] contraído pelo mosquito} ou sexualmente transmissivel"(G2).

Tais saberes respaldam-se em campa- nhas oficiais individualizantes sobre o que é esperado que a mulher faça em todo o período de gestação, seja através de medidas de proteção, antimosquito (repelentes de uso tópico, roupas com menor exposição da pele, telas domésticas, etc.), seja pelo uso de preservativo nas relações sexuais(19). Estas estão ancoradas na matriz biomédica de conhecimento que fortemente sustenta a assistência pré-natal nos serviços de saúde e que tem orientado a elaboração de manuais e protocolos de atendimento direcionados aos profissionais de saúde.

"[...] desde que eu descobri [a suspeita do ZIKV] eu estava fazendo acompanhamento, tava quinzenal [...] Depois do oitavo mês passou a ser semanal por conta que ela [a bebê] não tava desenvolvendo e a gente tá acompanhando pra ver se é por conta do vírus."(G3).

Os rápidos avanços nas tecnologias para o diagnóstico pré-natal de doenças e malformações fetais têm sido acompanhados pelo deslocamento da identificação de deficiências e condições específicas através de cálculos morfofuncionais e o controle de riscos, esmaecendo suas fronteiras no âmbito privado. Por exemplo, nas alterações congênitas graves, que inclui a SCZV, as opções de escolha das mulheres parecem bem restritas, pois a possibilidade de interrupção da gravidez por decisão própria é perpassada por elementos morais e burocrático-legais ${ }^{(20)}$.

Nesse sentido, o escrutínio dos fetos e os saberes científicos, mesmo que necessários sob a perspectiva biomédica, podem se tornar inúteis diante da inexistência de tratamento que possa interferir no desenvolvimento anormal do cérebro fetal e da impossibilidade jurídico-legal de escolha da mulher pela interrupção da gravidez no Brasil ${ }^{(20)}$. De modo que, questiona-se a que serve o diagnóstico pré- natal para além do estresse da mulher e família e do considerável consumo dos procedimentos biotecnológicos onerosos ao sistema de saúde (seja público ou privado)? 
No tópico seguinte destacam-se questões que envolvem as repercussões desse agravo no cotidiano de gestantes e de suas famílias, compreendendo quais as possíveis fontes de apoio que surgiram compondo a experiência.

\section{Repercussões e apoios cotidianos na gestação com suspeita ou diagnósti- co de Zika Vírus}

Os sentimentos relatados pelos participantes se mostram entre as repercussões mais imediatas geradas pela suspeita ou confirmação do diagnóstico do ZIKV durante a gestação, os quais incluem: $o$ medo, a frustração, as incertezas e os conflitos emocionais:

"Eu vim aqui pegar o resultado do exame, estou com medo" (G4).

"Eu fiquei desesperado, chorei, pensei muito o porquê disso acontecer, fiquei triste pra caramba, fiquei muito chateado" (Cônjuge).

"Chorei. Chorei bastante até antes de fazer a ultrassom por conta que ela [bebê] não tava desenvolvendo, não tava ganhando peso e ela não tava também no tamanho adequado. Eu fiquei bastante preocupada, né [...] fiquei até com dificuldade pra dormir" (G3).

Nota-se a intermediação das repercussões pelas tecnologias diagnósticas e sobre este aspecto, as reflexões da Sociologia do Diagnóstico podem fornecer elementos importantes a essa discussão ao trazer o diagnóstico como categoria, processo e consequência ${ }^{(21)}$. O diagnóstico intrauterino de microcefalia é mediado, portanto, duplamente pelo exame do corpo da mulher e do feto ${ }^{(20)}$, que se repercutem (consequências) de modo diferenciado em todos envolvidos ${ }^{(21,22)}$ - gestantes, cônjuges, família, etc.

"[...] até pra dormir, deito na cama e penso [...] poxa, será que minha filha vai nascer com problema de saúde, com algum defeito? [...] Eu fiquei desesperado [...] no mesmo dia levei no médico, sabemos que era zika, viemos pro hospital, já fizemos exames, já fomos no médico, fizemos ultrassom, mediram pra ver como que tava o formato da criança [...]" (Cônjuge).

Considerar a situação das gestantes e familiares em relação aos procedimentos diagnósticos permite abordar o diagnóstico como um ato, um processo interpretativo, que se desdobra em emoções, saberes e nas interações, em particular, com os serviços e profissionais de saúde, produzindo efeitos que repercutem muito além do hospital e/ou consultório do médico ${ }^{(21)}$ para espraiar-se nas interações e arranjos familiares ao incidir sobre seus planos e projetos futuros.

Contudo, as expectativas e os projetos de vida das famílias afetadas podem se reconfigurar a longo prazo, através de renegociações, decisões e iniciativas que abranjam os diferentes âmbitos da vida ${ }^{(8)}$ e redimensionamento de projetos futu$\operatorname{ros}^{(17)}$. Após a suspeita/diagnóstico do agravo, ocorreram mudanças na rotina familiar, especialmente da gestante, sendo requeridos maior tempo e dedicação durante o acompanhamento pré-natal, o que por vezes levou a deixar de lado outras atividades cotidianas, como casa, estudos, trabalho e lazer ${ }^{(7)}$.

"[...] agora vou ter que fazer um ultrassom por semana pra acompanhar o bebê. Pelos sintomas e pela diabetes [...]" (G2).

"[...] de uma hora pra outra, revira a vida da gente, mas é uma criança que está nascendo, é seu filho que está nascendo" (Cônjuge).

Além da rotina imposta pela própria gestação, período de significativas mudanças, soma-se que a família é demandada a se mobilizar e se reorganizar, ainda mais, para atender as necessidades geradas por essa circunstância incomum. As novas de- mandas podem impulsionar o rearranjo dos vínculos e das atividades rotineiras de cada familiar ${ }^{(23)}$, como evidenciado:

"Ela [a esposa] está indo várias vezes no postinho lá perto de casa, mas eu trabalho [...] aí, o meu pai busca ou o meu irmão [...]. Aqui no Hospital fica meio distante e eu tenho que acompanhar ela também, porque aqui eu não sei que horas vai terminar, demora" (Cônjuge).

A ação da família mostra-se fundamental nessa situação, principalmente quando há comprometimento dos planos para a gestação no bojo das incertezas do desenvolvimento fetal/infantil, o apoio da família pode ser acionado conforme as circunstâncias da vida e as necessidades cotidianas. Deste modo, a família pode se tornar um elemento estável que permitiria às pessoas encontrarem um sentido para a sua ação ${ }^{(24)}$. Todavia, as expectativas geradas em torno da família devem ser consideradas como possibilidades à vista e não garantias concretas. $\mathrm{O}$ apoio familiar não é incondicional e absoluto, pois depende do contexto sociocultural no qual se insere ${ }^{(25)}$.

Nesse contexto, o apoio familiar poderia reforçar as potencialidades com uma importante participação: o fortalecimento dos laços de solidariedades ${ }^{(24)}$ - que desempenha um papel fundamental na provisão das necessidades individuais e na prestação de diversos cuidados ao longo do ciclo de vida, como da gestação ao crescimento/desenvolvimento da criança, no qual cada membro da família se tornaria nó/nós ativos na prestação de cuidados e na manutenção da vida cotidiana ${ }^{(26)}$.

“[...] ele [o esposo], começou a acompanhar mais no pré-natal, um pouco mais de atenção que antes" (G3).

"ele [o esposo] dá apoio [...] [eu recebo] apoio da minha mãe [...]. Tenho falado muito com minha mãe, todos os dias eu converso com ela" (G4). 
Os depoimentos mostraram que, quando há uma preocupação ou necessidade durante a gestação, pessoas mais próximas podem se envolver com a situação/problema tornando-se parte essencial na rede de apoio - os nós mais fortes e ativos nos laços de solidariedade ${ }^{(24,26)}$. No entanto, esse fato não é uma norma social, pelo contrário, pois alguns estudos têm apontado o abandono e a falta de vínculos familiares ${ }^{(25,27)}$. De modo que, a influência da rede social pode se mostrar tanto de forma positiva quanto negativa ${ }^{(24)}$.

Quando atuam positivamente, as redes de apoio podem ser definidas pela disponibilidade de apoio a partir dos vínculos sociais significativos ${ }^{(24)}$, como no caso dos cônjuges e familiares da gestante, diante de situações de crise, dúvidas e preocupações, propiciando estratégias de enfrentamento através do encorajamento ou cuidado, principalmente, em períodos de transição e de grandes mudanças ${ }^{(28)}$.

Após o nascimento de um filho com alguma deficiência e/ou malformação congênita, a exemplo da SCZV, continuam a ocorrer mudanças na rotina, dinâmica e estrutura familiar, entre elas os custos financeiros demandados pelos cuidados contínuos, idas/vindas de consultas/exames específicos e especializados, bem como a constante necessidade de acesso a serviços de saúde ${ }^{(23)}$, nem sempre cobertos por planos de saúde, insumos/produtos (alimentares, de higiene, etc.) específicos e, igualmente, não cobertos ou subsidiados pelo sistema de saúde. Como apontado por uma gestante:

"[...] começa com fralda, roupas, acessórios, leite [...]. Tudo isso tem um gasto [...] A gente queria primeiro construir uma casa [...] E um filbo é uma casa construída, né?" (G2).

Relatos como evidenciaram certa vulnerabilidade econômica dessas famílias que, potencialmente, pode ser amplificada pela ocorrência de uma condição crônica.
As mais diversas necessidades sociais exigem suporte e melhor administração dos recursos financeiros, assim como, o estabelecimento de prioridades para a destinação desses recursos, que pode, a depender das condições financeiras de cada família, modificar projetos individuais/coletivos futuros $^{(18,22,23)}$.

"Eu estava com plano de fazer faculdade o ano que vem. Eu vou fazer, mas agora vai demorar mais" (G2).

Existiram diferentes fontes de apoio social às gestantes e suas famílias que receberam a notícia da suspeita/diagnóstico de infecção por ZIKV, que lhes ajudaram no dessa fase crítica ${ }^{(28)}$. Uma dessas fontes foi a fé:

"Mas a gente tem fé em Deus que vai dar tudo certo [...] No meu coração, do jeito que Deus mandar pra mim vai ser bem vinda" (Cônjuge).

"Todo mundo [da família] orando
pra dar tudo certo" (G3).

A fé pode ser compreendida como uma manifestação da espiritualidade que proporciona esperança, conforto e bem-estar, na tentativa de superar as adversidades geradas pela notícia, auxiliando na aceitação e minimizando sofrimento e ansiedade ${ }^{(6,7)}$. Não obstante, há de se ponderar as questões morais que permeiam o ser mulher e o ser mãe, exigindo uma conduta de devoção e missão quase que inescapável:

"Deus nunca dá um fardo pra gen-
te, que a gente não consiga carregar
[...] com certeza ia ter que ter uma
adaptação, porque mãe é mãe, né?
Mãe não importa. O filho pode vir
sem a perna, sem o braço, sem ca-
belo, pelado, do jeito que for [...] A
gente aceita do mesmo jeito" (G2).

Sobre as questões morais adjacentes, Löwy ${ }^{(20)}$ aponta criticamente o peso que recai, sobretudo, às mulheres ao assumir as consequências do nascimento de seus filhos e dos respectivos cuidados permanentes e agravados progressivamente, a depender do grau de dependência - cujo prognóstico é reconhecidamente impreciso. Destarte, homens e mulheres, em medida desigual, respondem às questões morais que estão implicadas na experiência do cuidar dos filhos, todavia, as trajetórias biográficas estão sensíveis aos contextos em que se inserem e se expressam de diferentes formas, sendo impelidos por um conjunto de códigos culturais das diversas matrizes de significados ${ }^{(18)}$, entre elas, a matriz religiosa - tradicional e extremamente fértil à compreensão da experiência em tela.

\section{CONSIDERAÇÕES FINAIS}

Compreender a experiência de gestantes com suspeita/diagnóstico de ZIKV implicou em reconhecer e valorizar os aspectos subjetivos que marcaram a trajetória de vidas, os saberes mobilizados e os contextos, para ampliar o olhar sobre a realidade das mesmas e para, potencialmente, atuar de forma mais sensível, levando em conta os aspectos socioculturais.

A experiência revelou significativas mudanças no cotidiano da gestante e dos que estavam em sua volta, promovendo a reorganização dos vínculos sociais e alcançando dimensões da vida privada, com destaque para dimensão socioeconômica e espiritualidade. Além disso, repercutiu nas projeções e planos familiares, no compasso de questôes morais que sedimentaram as ações e escolhas na esfera pública e privada.

Nesse sentido, as repercussóes se revelaram no entrelaçamento de elementos materiais e imateriais/simbólicos, clínicas e sociais, de modo dinâmico e marcante, alcançando pessoas em seu entorno (familiares, profissionais de saúde, etc.) na tessitura das redes de apoio social. No entanto, o apoio social não deve ser fornecido apenas pelas pessoas e pelas suas relações, pesando sobremaneira na individualização e na responsabilização 
da família no bem-estar social ${ }^{(25)}$, mas prioritariamente pela responsabilização do Estado-providência quanto ao aparato jurídico-legal, políticas públicas, sistema de recursos e serviços sociais, em resposta a um problema de saúde pública.

Os afetamentos gerados pelas repercussões/impactos se somam e, por vezes, se confundem a outras questões de ordem social, imbricando-se. De modo que, ampliar o contexto estudado para abarcar aspectos estruturantes (classe, gênero, políticas sociais, etc.) ao compreender a experiência das famílias afetadas pelo ZIKV ainda se torna essencial.

Portanto, a compreensão do fenômeno estudado não se esgota, nem pode ser dada como pronta e acabada. É necessário explorá-lo e analisá-lo em diferentes contextos socioculturais a partir de diversos pontos de vista dos sujeitos envolvidos. Enfim, almeja-se que as reflexões trazidas possam instigar outros estudos desta natureza envolvendo a presente temática, em especial, na vertente socioantropológica, que muito tem contribuído em pesquisas no campo da saúde.

\section{REFERÊNCIAS}

1. World Health Organization. Neurological syndrome, congenital malformations, and Zika virus infection. Implications for public health in the Americas. Geneva; 2015.

2. Centers for Disease Control and Prevention. Zika em bebês e crianças. Atlanta; 2016.

3. Ministério da Saúde (BR). Orientações integradas de vigilância e atenção à saúde no âmbito da Emergência de Saúde Pública de Importância Nacional. Brasília (DF): Secretaria de Vigilância à Saúde; 2017.

4. Eickmann $S$, et al. Síndrome da infecção congênita pelo vírus Zika. Cad. Saúde Pública. 2016; 32(7):1-3.

5. Tolulope AMD, et al. Update: Interim Guidance for the Diagnosis, Evaluation, and Management of Infants with Possible Congenital Zika Virus Infection. MMWR Morbidity and mortality weekly report. 2017; 66(41):1089-1099.

6. Rocha MCP, et al. Experiência da família da criança com microcefalia. Saúde Revista. Piracicaba. 2015; 15(40):49-66.

7. Freitas AAF. Avaliação do impacto familiar em pais de crianças diagnosticadas com microcefalia pelo Zika Vírus [dissertação]. Goiânia: Pontifícia Universidade Católica de Goiás; 2018.

8. Adam P, Herzlich C. Sociologia da doença e medicina. Bauru: EDUSC; 2001.

9. Schutz A. Sobre a fenomenologia e relações sociais. Petrópolis: Editora Vozes; 2012.

10. Alves PC. A fenomenologia e as abordagens sistêmicas nos estudos sócio- antropológicos da doença: breve revisão crítica. Caderno de Saúde Pública. 2006; 22(8):1547-1554.

11. Alves PC. A experiência da doença: considerações teóricas. Cadernos de Saúde Pública. 1993; 9(3):239-262.

12. Minayo MC. Amostragem e Saturação em Pesquisa Qualitativa: consensos e controvérsias. Revista Pesquisa Qualitativa. 2017; 5(7):01-12.

13. Gomes R. Análise e interpretação de dados de pesquisa qualitativa. In: Minayo MCS, Deslandes SF, Gomes R, organizadores. Pesquisa Social: teoria, método e criatividade. 30. ed. Petrópolis: Vozes; 2011. p. 79-108.

14. Rabelo MC, Alves PCB, Souza IMA (org.). Experiência de doença e narrativa. Rio de Janeiro: Editora Fiocruz; 1999.
15. Barsaglini RA, Biato ECL. Compaixão, piedade e deficiência física: o valor da diferença nas relações heterogêneas. História, Ciências, Saúde-Manguinhos. 2015; 22(3):781-796.

16. Goffman E. Estigma: notas sobre a manipulação da identidade deteriorada. 4. ed. São Paulo: LTC; 1988. Tradução: Lambert M.; 2004.

17. Velho G. Projeto e metamorfose: antropologia das sociedades complexas. 3. ed. Rio de Janeiro: Jorge Zahar Ed; 2003.

18. Amaral VM, Laguardia J. Mídia e risco à saúde: $\mathrm{O}$ caso dos emagrecedores nas revistas semanais de informação. Peru: ALAIC; 2014.

19. Ministério da Saúde (BR). Atenção ao pré-natal de baixo risco. Cadernos de Atenção Básica. Brasília (DF): Secretaria de Atenção à Saúde; 2012.

20. Löwy I. Imperfect pregnancies: a history of birth defects and prenatal diagnosis. Baltimore: Johns Hopkins University Press; 2017.

21. Jutel A. Putting a name to it: diagnosis in contemporary society. Foreword by Peter Conrad, Johns Hopkins University Press; 2011.

22. Oliveira MC, Sá SM. A experiência parental após o diagnóstico da microcefalia por Zika vírus: Um estudo de caso. Revista Pesquisa em Fisioterapia. 2017;7(4):64- 70.

23. Baltor MRR, Dupas G. Experiências de famílias de crianças com paralisia cerebral em contexto de vulnerabilidade social. Revista Latino Americana de Enfermagem. 2013; 21(4).

24. Portugal S. Família e redes sociais: Ligações fortes na produção de bem-estar. Coimbra: Edições Almedina; 2014.

25. Carvalho MCB. O lugar da família na política social. In: CARVALHO MCB et al., organizadores. A família contemporânea em debate. 4. ed. São Paulo: EDUC/Cortez; 2005.

26. Portugal S, Nogueira C, Hespanha P. As Teias que a Doença Tece. DADOS - Revista de Ciências Sociais. 2014; 57(4).

27. Cruz GVSF. "Microcefalia não é o fim": experiência de famílias no contexto da condição crônica [tese]. Cuiabá: Faculdade de Enfermagem da Universidade Federal de Mato Grosso; 2019.

28. Andrade MN. Perfil sociodemográfico e sentimentos vividos por gestantes com malformação fetal [dissertação]. Goiânia: Universidade Federal de Goiás; 2014. 